\title{
Research Paper Plasma Neurofilament Light Combined with Risk Genes for the Diagnosis of Alzheimer's Disease
}

\author{
S. Z. ZHANG*, F. MEI'1 , M. L. GAO², LI ZHANG, LI MA, HAIYAN WU, L. X. LIU, M. CAO AND X. L. HE
}

Psychiatry Department, Beijing Geriatric Hospital, Beijing 100095, 'Institute of Systems Biomedicine, Department of Pathology, School of Basic Medical Sciences, Peking University Health Science Center, Beijing 100191, 2Institute of Geriatric Health, Beijing Geriatric Hospital, Beijing 100095, China

\section{Zhang et al.: Plasma Neurofilament Light Combined with Risk Genes in Alzheimer's Disease}

To explore the association of plasma neurofilament light and other potential biomarkers with the neurodegeneration in Alzheimer's disease is the objective. Alzheimer's disease is a progressive neurodegenerative disease. The levels of amyloid beta, total tau, phosphorylation tau protein in the cerebrospinal fluid were well-accepted biomarkers for clinical diagnosis of Alzheimer's disease. However, invasive acquisition of cerebrospinal fluid limits its clinical application. In recent years, studies on plasma biomarkers for Alzheimer's disease were increasing. 112 probable Alzheimer's disease cases and 96 normal cognitive control group were included. The cognition and psychobehavioral symptoms were measured. The plasma level of amyloid beta, total tau and neurofilament light were measured by the method of single molecule array. Apolipoprotein genotype and Alzheimer's disease risk genes were examined. Of all the included participants, the plasma neurofilament light level in patients with Alzheimer's disease dementia was significantly increased compared with normal cognitive control group (mean levels: 64.68 $\mathrm{ng} / \mathrm{l}$ vs. $40.66 \mathrm{ng} / \mathrm{l} ; \mathbf{p}<0.001)$. The area under the curve value of neurofilament light was 0.861 , with the sensitivity (0.892), specificity (0.769) and cut-off value (42.440), suggesting that neurofilament light had high diagnostic value for Alzheimer's disease. In probable Alzheimer's disease group, the plasma neurofilament light level have a negative correlation with the mini-mental state examination score and a positive correlation with the plasma amyloid beta-42 level $(\mathrm{p}<0.01)$. The logistic regression analysis showed that the plasma neurofilament light, tau concentration and Alzheimer's disease risk gene have a significant positive impact on Alzheimer's disease morbidity $(p<0.05)$. These findings suggest that plasma neurofilament light combined with Alzheimer's disease risk genes may be used as diagnosis biomarkers in patients with Alzheimer's disease.

Key words: Alzheimer's disease, neurofilament light, Alzheimer's disease susceptibility genes variation, amyloid beta, tau, ultra-sensitive single molecule array

Neurofilament light (NFL) is a $68 \mathrm{kDa}$ cytoskeletal intermediate filament protein expressed in neurons. It associates with the $125 \mathrm{kDa}$ neurofilament medium (NFM) and the $200 \mathrm{kDa}$ neurofilament heavy (NFH) to form neurofilaments. They are major components of the neuronal cytoskeleton and are suggested to provide structural support for the axon and to regulate axon diameter. Neurofilaments can be released in significant quantity following axonal damage or neuronal degeneration ${ }^{[1]}$. NFL has been shown to associate with traumatic brain injury, multiple sclerosis, frontotemporal dementia and other neurodegenerative diseases. The amyloid- $\beta(A \beta)$ deposition and pathologic tau within cerebrospinal fluid (CSF) are well-accepted biomarker for diagnosis of Alzheimer's disease (AD) in clinical practice. The imaging markers including volumetric magnetic resonance imaging (MRI) or positron emission tomography (PET) of glucose metabolism, $\mathrm{A} \beta$ and tau aggregates are also playing an important role in the diagnosis and monitoring the neurodegeneration of $\mathrm{AD}^{[2]}$. In recent years, the ultrasensitive modern immune-complex-based technologies were adopted to detect the levels of $A \beta$ peptide, tau and NFL in the plasma and serum. These methods depend on the immunomagnetic reduction technology (IMR) and single molecule array (SIMOA) technology,

*Address for correspondence

E-mail: lanczsz@126.com 
which have been proved to provide a noninvasive, inexpensive and readily available biomarkers to track the neurodegenerative process in $\mathrm{AD}^{[3]}$.

Another biomarker of $\mathrm{AD}$ is risk genes. Presenilin (PSEN1/2) genes and amyloid precursor protein (APP) gene are linked to early-onset familial AD (EO-FAD). By contrast, allelic variation in apolipoprotein E4 (ApoE4) and many other genes such as ATP-binding cassette transporter A1 (ABCA1) are linked to lateonset sporadic AD (LO-SAD $)^{[4]}$. Detection of risk genes associated with neurodegeneration has been applied to the prediction and diagnosis of $\mathrm{AD}$ and other dementia disease.

As a sensitive biomarker for neuroaxonal damage, the NFL in CSF has been proved to be correlated to other AD biomarkers. However, it cannot be utilized to diagnose $\mathrm{AD}$ alone, owing to less specificity. In this study we designed a paradigm to detect serum NFL tau $\mathrm{A} \beta$ level combined with the genetic test and examined whether serum NFL levels are associated with other measures and plays a diagnosis role in AD.

\section{MATERIALS AND METHODS}

\section{Participants:}

112 probable $\mathrm{AD}$ patients were recruited from the psychiatry department in Beijing Geriatric Hospital between August 2019 and August 2020. All the patients underwent cognitive psychology scale evaluation and neuroimaging measurement, according to the National Institute on Aging and Alzheimer's Association (NIAAA) diagnostic criteria published in $2011^{[5]}$. All the participants have cognitive impairment with mild, moderate and severe degree and a Mini-Mental State Examination (MMSE) scores between 0 and 23, clinical dementia rating scale (CDR) scores from 1.0 to 3.0. There were no significant differences in age and sex between the two groups of participants. They all have no severe disease history other than AD. 96 participants over 65 y old were recruited as normal control who reported MMSE score of 26 or higher and CDR score of zero. They have no mental illness, surgery or other major disease history, without dementia patients in their families. Consensus agreements were signed by participants or their custodians. Regional ethical committees of Beijing Geriatric Hospital institutions approved this study.

\section{Measures of plasma NFL and other biochemical markers:}

$10 \mathrm{ml}$ venous blood sample was drawn into ethylenediamine tetraacetic acid (EDTA) tube from every subject. The blood samples were centrifuged at $2500 \times \mathrm{g}$ for $15 \mathrm{~min}$, stored at $-80^{\circ}$. Plasma NFL level was measured at the Beijing Kingmed Clinical Laboratory, using SIMOA technology on a single molecule array platform (Quanterix Corp). The mechanism and technology of SIMOA have been reported ${ }^{[3]}$. The details of Neuro-4-plexp that analyzed $A \beta$ and tau levels were also available at the company's website (www. quanterix.com). Simoatm NF-light reagent kit was used to test NFL level, the calibration range was $0 \sim 450$ $\mathrm{pg} / \mathrm{ml}$ and dynamic range was $0 \sim 1800 \mathrm{pg} / \mathrm{ml}$ (plasma and serum). The measurements were performed from January $1^{\text {st }}$ to April $1^{\text {st }}, 2020$, by a board-certified laboratory technician using a single batch of reagents.

\section{Cognitive tests:}

Cognition was assessed using the MMSE, neuropsychiatric inventory (NPI) and the CDR by neurologists.

\section{Whole exome sequencing and analysis of candidate genes:}

The whole exome sequencing (WES) was performed on deoxyribonucleic acid (DNA) from peripheral blood. After the processes of fragmenting the genomic DNA, ligating the paired end adaptor, amplifying and purifying, all human exons and the 20 bp bases in their adjacent introns were captured by $x$ Gen $^{\circledR}$ Exome Research Panel. The DNA library was performed postcapture amplification and purifying and then sequenced by the Illumina HiSeq sequencing platform.

Sequence data alignments to the human genome reference (hg19) and variants calling were used by NextGene V2.3.4 software, further to get the coverage and mean read depth of the target regions. The mean read depth was $158.56 \times$ and even it reached to $20 \times$ for 99.5 $\%$ of the target sequences. Meanwhile, the annotation information, including the conservation of nucleotide bases and amino acid, predictions of the biological functions, frequency of the normal populations (1000 Genomes Project, ExAC, dbSNP database and locus specific databases) and the data from Human Gene Mutation Database (HGMD), ClinVar and Online Mendelian Inheritance in Man (OMIM), was performed by NextGene V2.3.4 and lab's own scripts.

Variants were screened as followed: Preference to the variants related to the diseases, Small insertions and deletions (INDELs), canonical splice sites and missense variants. Minor allele frequency in normal populations $<5 \%$ (except for the known MAF $>=5 \%$ 
pathogenicity), Preference to the variants in HGMD and ClinVar and preference to the variants in OMIM. The variants of pathogenicity were according to standards and guidelines for the interpretation of sequence variants published by American College of Medical Genetics and Genomics (ACMG) in 2015 with Human Genome Variation Society (HGVS) nomenclature. Roundabout Guidance Receptor 1 (ROBO1) gene has three transcripts in National Center for Biotechnology Information (NCBI) and we used NM_002941.3 as the reference sequence for analysis.

\section{Apolipoprotein E genotyping:}

APOE genotyping was carried out as previously reported ${ }^{[6]}$.Genomic DNA was amplified, using primers as follows: forward TCCAAGGAGCTGCAGGCGGCGCA, reverseACAGAATT CGCCCCGGCCTGGTACACTGCCA. Amplification product was then digested with five Hhal for $2 \mathrm{~h}$ at $37^{\circ}$ and subjected to electrophoresis. The genotypes were determined by the size of DNA fragment.

\section{Statistical analysis:}

Data were expressed as mean \pm standard deviation (SD) or an absolute number and SPSS software was used. Spearman correlation analysis was applied to examine the correlations between plasma NFL measures, plasma $\mathrm{A} \beta$ measures, plasma tau measures, cognitive tests and AD risk gene. Receiver operating characteristic (ROC) curve analysis for each plasma biomarkers was used to diagnose AD. Multivariate logistic regression model was built to further evaluate the associations between AD morbidity and plasma NFL measures, AD risk gene, plasma $A \beta$ measures and tau measures. A p-value of 0.05 or 0.01 was defined as the threshold of statistical significance in each test.

\section{RESULTS AND DISCUSSION}

As illustrated in Table 1, the demographics, cognitive and neuropsychiatric scores, APOE $\varepsilon 4$ carrier status and other AD susceptibility genes. We included 96 cognitive intact controls. The mean of age was 81 $y$ old, rate of male sex was $41.6 \%$ and the mean of MMSE was 28. The total number of patients with AD susceptibility genes was 10,2 people with APOE $\varepsilon 4+/+$ gene, 8 with APOE $\varepsilon 4+/$ - gene. 112 AD dementia subjects were included of which the mean age was 84 y old, rate of male sex was $48.2 \%$, the mean of MMSE was 6.4 , the mean of NPI was 15 . The total number of patients who carry with AD susceptibility genes was 34, 9 persons with APOE $\varepsilon 4+/+$ gene, 20 persons with
APOE $\varepsilon 4+/$ - gene, one person carrying heterozygous variation of APP gene (p.693 Glu>Gly), one person with heterozygous variation of PSEN1 gene (c.356C $>$ T), one person with heterozygous variation of alpha-2macroglobulin (A2M) gene (c.4198G $>$ A), one person with heterozygous variation of presenilin 2(PSEN 2) gene (c.1186c $>A$ ), one person with heterozygous variation of $A B C A 7$ gene (p.578Arg $>$ fs).

Table 1 and fig. 1 showed that plasma NFL concentration was significantly higher in $\mathrm{AD}$ group than in controls (79.89 pg/ml vs. $48.70 \mathrm{pg} / \mathrm{ml} ; \mathrm{p}=0.001)$, plasma tau concentration was significantly higher in $\mathrm{AD}$ group than in controls $(6.26 \mathrm{pg} / \mathrm{ml}$ vs. $3.84 \mathrm{pg} / \mathrm{ml} ; \mathrm{p}=0.001)$. But there were no difference for plasma amyloid- $\beta 40$ (A $\beta 40)$ and amyloid- $\beta 42$ (A $\beta 42)$ levels between $A D$ group and normal controls $(4.85 \mathrm{pg} / \mathrm{ml}$ vs. $4.06 \mathrm{pg} / \mathrm{ml}$ and $81.74 \mathrm{pg} / \mathrm{ml}$ vs. $98.00 \mathrm{pg} / \mathrm{ml}$; all $\mathrm{p}>0.05)$.

TABLE 1: COMPARISON OF TEST RESULTS IN EACH GROUP

\begin{tabular}{|c|c|c|}
\hline Measures & Normal control & $A D$ \\
\hline Total patients, No. & 96 & 112 \\
\hline Age, mean (SD) & $81(5.498)$ & $84(6.827)$ \\
\hline Male sex, No. (\%) & $40(41.6 \%)$ & $54(48.2 \%)$ \\
\hline MMSE score, mean (SD) & $28(1.938)$ & $0(6.413)$ \\
\hline NPI score, mean (SD) & / & $15(9.441)$ \\
\hline $\begin{array}{l}\text { AD susceptibility genes, } \\
\text { No. }\end{array}$ & 10 & 35 \\
\hline APOE $\varepsilon 4+/+$, No. & 2 & 9 \\
\hline APOE $\varepsilon 4+/-$, No. & 8 & 20 \\
\hline APP gene variation, No. & 0 & 1 \\
\hline $\begin{array}{l}\text { PSEN1 gene variation, } \\
\text { No. }\end{array}$ & 0 & 1 \\
\hline $\begin{array}{l}\text { PSEN2 gene variation, } \\
\text { No. }\end{array}$ & 0 & 1 \\
\hline A2M gene variation, No. & & 1 \\
\hline $\begin{array}{l}\text { ABCA7 gene variation, } \\
\text { No }\end{array}$ & 0 & 1 \\
\hline $\begin{array}{l}\text { B-Amyloid } 42 \text { mean (SD) } \\
\mathrm{ng} / \mathrm{l}\end{array}$ & $4.85(3.00)$ & $4.06(2.82)$ \\
\hline $\begin{array}{l}\text { B-Amyloid } 40 \text { mean (SD) } \\
\mathrm{ng} / \mathrm{l}\end{array}$ & $81.746(41.9)$ & $89(59.576)$ \\
\hline Total tau mean (SD) ng/l & $6.26(3.78)$ & $3.84(1.83)$ \\
\hline NFL mean $(S D) \mathrm{ng} / \mathrm{l}$ & $79.89(44.53)$ & $48.70(42.05)$ \\
\hline
\end{tabular}

Note: MMSE=Mini-mental state examination, NPI=Neuropsychiatric inventory, $N F L=$ neurofilament light protein, $A B=$ amyloid $-B$

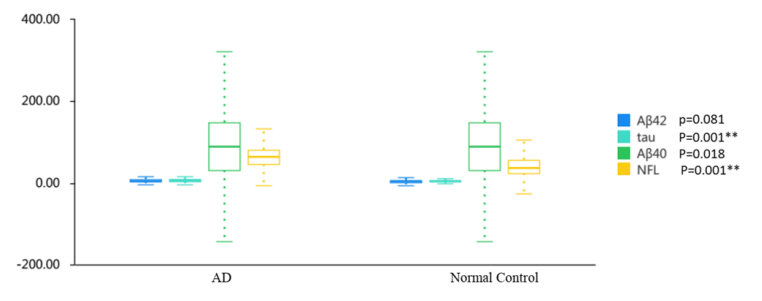

Fig. 1: NFL, Aß42, Aß40, tau slopes by clinical diagnosis 
We also analyzed relationships across AD biomarkers (NFL, A $\beta 42, A \beta 40$, tau, AD susceptibility genes) and AD clinical features (Age, MMSE, NPI). In 112 AD participants, there was negative correlation between plasma NFL concentration and MMSE $(\beta=-0.456$, $\mathrm{p}=0.001$ ) and positive correlation between plasma NFL concentration and $A \beta 42$ concentration $(\beta=0.424$, $\mathrm{p}=0.002$ ). In $\mathrm{AD}$ group, there was a positive correlation between $\mathrm{AD}$ risk genes and age $(\beta=-0.584, \mathrm{p}<0.001)$, there were no relationship between $\mathrm{AD}$ risk genes and other variables (Table 2).

In the ROC analyses, the area under the curve (AUC) for the comparisons between normal controls and those with AD was 0.556 (95\% confidence interval (CI) 0.471-0.640) for plasma A $\beta 42,0.491$ (95\% CI 0.4060.577 ) for $A \beta 40$. By contrast, the AUC of plasma NFL was 0.743 (95\% CI 0.656-0.812) for control individuals versus those with AD was 0.745 (95\% CI 0.676-0.815) for control individuals versus those with AD. Using a cutoff of $54.2 \mathrm{pg} / \mathrm{ml}$ for NFL, the sensitivity was $73.6 \%$ and specificity $68.9 \%$ for differentiating normal control from AD dementia. While using a cutoff of $6.34 \mathrm{pg} / \mathrm{ml}$ for tau, the sensitivity was $49.1 \%$ and specificity 91.9 $\%$ for differentiating normal control from $\mathrm{AD}$ dementia (Table 3 and fig. 2).

We used plasma $A \beta 42$, tau, $A \beta 40$, NFL, $A \beta 42 / A \beta 40$ and $\mathrm{AD}$ risk genes as independent variables, while $\mathrm{AD}$ morbidity was used as dependent variable for logistic regression analysis. These results showed that the regression coefficient of plasma tau was 0.384 , suggesting that plasma tau has a significant positive impact on AD morbidity $(\mathrm{z}=4.381, \mathrm{p}<0.001)$. The regression coefficient of plasma NFL was 0.013 , indicating that plasma NFL has a significant positive impact on $\mathrm{AD}$ morbidity $(\mathrm{z}=2.525, \mathrm{p}=0.012)$. The regression coefficient of $\mathrm{AD}$ gene was 2.382 , showing that AD susceptibility genes has a significant positive impact on $\mathrm{AD}$ morbidity $(\mathrm{z}=4.809, \mathrm{p}<0.001)$. However, other biomarkers didn't impose impact on AD morbidity (Table 4).

\section{TABLE 2: VARIABLES ASSOCIATED WITH PLASMA NFL MEASURES AND AD SUSCEPTIBILITY GENES}

\begin{tabular}{lcccccc}
\hline Measures & \multicolumn{3}{c}{ Plasma NFL } & \multicolumn{3}{c}{ AD susceptibility genes } \\
\cline { 2 - 7 } & $\mathbf{B}$ & $\mathbf{p}$ value & $\mathbf{R}^{2}$ & $\mathbf{B}$ & $\mathrm{p}$ value & $\mathbf{R}^{2}$ \\
\hline Age & -0.205 & 0.172 & 0.094 & 0.584 & $0.000^{* *}$ & 0.212 \\
MMSE & -0.456 & $0.001^{* *}$ & 0.208 & -0.213 & 0.155 & 0.038 \\
NPI & 0.19 & 0.206 & 0.038 & 0.129 & 0.394 & 0.038 \\
AB42 & 0.424 & $0.002^{* *}$ & 0.2 & 0.041 & 0.776 & 0.165 \\
AB40 & 0.163 & 0.279 & 0.056 & 0.232 & 0.121 & 0.056 \\
Tau & 0.266 & 0.062 & 0.107 & 0.026 & 0.856 & 0.011 \\
NFL & $/$ & $/$ & $/$ & 0.029 & 0.839 & / \\
AD susceptibility & 0.029 & 0.839 & 0.071 & $/$ & & $/$ \\
genes & & &
\end{tabular}

Note: ${ }^{*} \mathrm{p}<0.05,{ }^{* *} \mathrm{p}<0.01$

TABLE 3: THE BIOMARKERS CUT-OFF RESULT OF ROC FOR DIAGNOSIS OF AD

\begin{tabular}{lcccccc}
\hline Title & AUC & Cut-off value & Sensitivity & Specificity & p value & $95 \% \mathrm{Cl}$ \\
\hline AB42 & 0.556 & 5.34 & 0.436 & 0.73 & 0.196 & $0.471 \sim 0.640$ \\
AB40 & 0.491 & 39.07 & 0.655 & 0.351 & 0.893 & $0.406 \sim 0.577$ \\
Tau & 0.745 & 6.34 & 0.491 & 0.919 & $0.001^{* *}$ & $0.676 \sim 0.815$ \\
NFL & 0.734 & 54.2 & 0.736 & 0.689 & $0.001^{* *}$ & $0.656 \sim 0.812$ \\
\hline
\end{tabular}

Note: ${ }^{*} \mathrm{p}<0.05,{ }^{* *} \mathrm{p}<0.01$

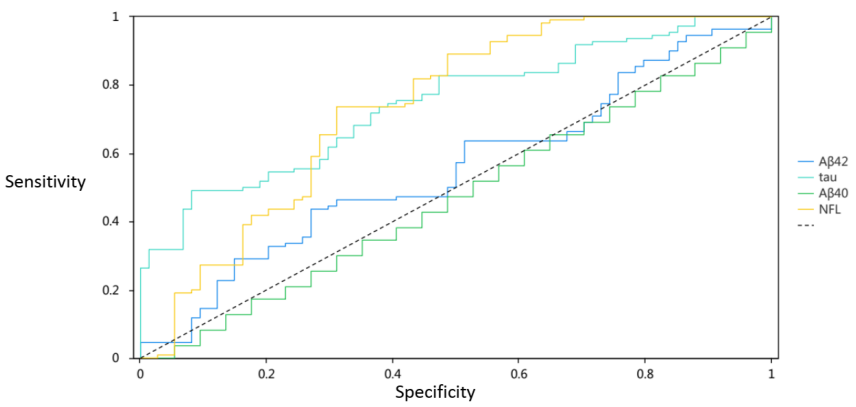

Fig. 2: ROC curve for biomarkers to diagnosis of AD 
TABLE 4: MULTIVARIATE LOGISTIC ANALYSIS FOR DIAGNOSIS OF AD

\begin{tabular}{lcccc}
\hline Measures & Regression coefficient & z value & p value & Odds ratio (OR) \\
\hline NFL & 0.013 & 2.525 & $0.012^{*}$ & 1.013 \\
AB42 & 0.075 & 1.065 & 0.287 & 1.078 \\
AB40 & -0.002 & -0.569 & 0.569 & 0.998 \\
AB42/AB40 & -1.294 & -0.160 & 0.873 & 0.274 \\
Tau & 0.384 & 4.381 & $0.000^{* *}$ & 1.468 \\
AD susceptibility genes & 2.382 & 4.809 & $0.000^{* *}$ & 10.829 \\
\hline
\end{tabular}

Note: ${ }^{*} p<0.05,{ }^{* *} p<0.01$

Many literatures have postulated a potential application of the plasma concentration of the light chain of the neurofilament protein as biomarkers for $\mathrm{AD}$ and other neurodegeneration disease. In this study, the plasma NFL concentration was found to be significantly higher in the $\mathrm{AD}$ patients than the cognitive intact controls. This finding replicates the previous findings. Niklas Mattsson have reported that the plasma NFL level is a dynamic biomarker that changes throughout the course of $\mathrm{AD}$ and is sensitive to the progression of neurodegeneration. His study revealed rates of NFL were correlated with rates of cognitive and imaging measures in $\mathrm{AD}$ groups ${ }^{[7]}$. After correcting for age, the difference in serum NFL concentrations between AD groups and cognitive impairment controls remained significant ${ }^{[8]}$. A positive association between NFL in CSF (cNFL) levels and age was also observed in individuals with most neurodegenerative conditions including $\mathrm{AD}$, vascular dementia $(\mathrm{VaD})$ and dementia with lewy bodies (DLB), but not in frontotemporal dementia (FTD ${ }^{[9]}$. Within the $\mathrm{AD}$ group, we also observed the relationship between plasma concentration of NFL and AD susceptibility genes phenotype, plasma concentration of $A \beta 42, A \beta 40$, tau, age and cognitive decline. We have not found positive association between plasma NFL and age, neither between plasma NFL and plasma tau as suggested by several previous studies in CSF and plasma ${ }^{[7,8]}$. By contrast, we have verified a positive association between plasma NFL and plasma $A \beta 42$. These data suggest that $A \beta$, tau pathologic features and degeneration of different types of axons are present in $\mathrm{AD}$, which will be weakly correlated overall. An inverse correlation between NFL and cognitive status measured by the MMSE is in line with the recently published results ${ }^{[10]}$. Some studies have revealed that the CSF biomarkers (tau, A $\beta 42$ ) were not correlated with the MMSE score after controlling for the diagnostic categories, supporting the notion that the CSF biomarkers do not correlate with disease progression at the stage of mild cognitive impairment (MCI) and later ${ }^{[11,12] .}$

The AD dementia group had higher plasma NFL levels and plasma tau levels than the controls (AUC 0.734 vs. $0.745, \mathrm{p}<0.01)$, with a lower specificity $(0.689$ vs. 0.919). The data indicates that plasma NFL as a peripheral biomarker for neuronal injury has shown diagnostic accuracy for AD dementia, comparable with established biomarkers in other large scale multicenter cohorts. Biomarkers, such as tau and NFL represent neuronal injury (e.g., axonal degeneration), while tau is a weaker marker for neuronal injury ${ }^{[13]}$.

We also detected gene polymorphism of APOE $\varepsilon 4$ and identified susceptible genetic variation for $\mathrm{AD}$ and established the relationship between plasma NFL and $\mathrm{AD}$ risk gene. The possible pathogenic gene includes $\mathrm{ABCA} 1, \mathrm{ABCA} 7^{[14,15]}$, histocompatibility locus antigen (HLA class III) ${ }^{[16,17]}$, triggering receptor expressed on myeloid cells 2 (TREM 2) ${ }^{[18]}, \mathrm{A}^{2} \mathrm{M}^{[19]}$, etc. In the multinomial logistic regression analysis APOE $\varepsilon 4+/+$ together with other AD risk gene play a significant positive role on $\mathrm{AD}$ morbidity. While the plasma NFL and tau concentration play positive effect on AD morbidity. These three biomarkers are salient features for AD. The most common form of familial Alzheimer's disease (FAD) is associated with mutations of the PSEN1/2 genes $^{[20,21]}$ and mutations of the APP gene $^{[22,23]}$. The early genetic studies of APP, PSEN1 and PSEN2 led to the establishment of $A \beta$ peptide as a critical molecule in $\mathrm{AD}$ pathogenesis. ApoE $\& 4$ may accelerate the development of AD pathology, associated with an earlier disease onset ${ }^{[24]}$. These genes have been identified as causal or risk factors for FAD patients. The lifetime risk for AD in individuals with APOE $\varepsilon 4 /$ $\varepsilon 4$ genotype is high, estimated as $33 \%$ or $32 \%$ for men or women by age $75 \mathrm{y}$; by age $85 \mathrm{y}$, the risk rate climbs to $52 \%$ for men and $68 \%$ for women ${ }^{[25]}$. Our study also confirmed a positive correlation between AD susceptibility genes and age. Cleavage of APP results in the formation of a variety of $\mathrm{A} \beta$ peptides ${ }^{[26]}$, which may be initiating factors for neurodegeneration. There was no statistically relationship between AD risk gene and NFL in our AD control. One interpretation of this is that NFL reflects neurodegeneration that occurred independent of gene mutations. Other 
neurodegenerative conditions and brain injury due to cardiac arrest may trigger neuronal injury leading to increased NFL concentration ${ }^{[27-29]}$. Pathological studies have verified that there is no difference between the levels of neurofibrillary tangles present in $\mathrm{AD}$ due to PSEN1 or PSEN2 mutations or in "sporadic" $\mathrm{AD}^{[30,31]}$, indicating that $\mathrm{AD}$ risk gene have no exacerbation of $\mathrm{AD}$ pathology. The biological function of the late-onset AD susceptibility genes are partially unknown. The role of each gene and its relationship between genes and other biomarkers like NFL and tau in AD pathogenesis will require more investigation.

From above, we postulate a proposal that potential application of the plasma NFL as a screening tool for neurodegeneration for $\mathrm{AD}$, while the CSF biomarkers for the confirmation of the diagnosis of AD. Plasma NFL together with demographics, APOE $\varepsilon 4$ genotype and other AD susceptibility genes may be used to predict $\mathrm{AD}$ morbidity and disease progression.

\section{Author's contributions:}

Shouzi Zhang designed the study strategy. Li Zhang, Li Ma, Haiyan Wu, Lixin Liu, Meng Cao and Xuelin He recruited the participants and collected their information and blood samples. Maolong Gao performed the data analysis, data management. Shouzi Zhang and Fan Mei wrote the manuscript. All authors reviewed the manuscript.

\section{Ethics statements:}

Studies involving animal subjects: No animal studies are presented in this manuscript.

Studies involving human subjects: The studies involving human participants were reviewed and approved by Beijing Geriatric Hospital. The patients/ participants provided their written informed consent to participate in this study.

Inclusion of identifiable human data: No potentially identifiable human images or data is presented in this study.

Data availability statement: All datasets generated for this study are included in the manuscript supplementary files.

\section{Conflicts of interest:}

The authors declare that the research was conducted in the absence of any commercial or financial relationships that could be construed as a potential conflict of interest.

\section{REFERENCES}

1. Preische O, Schultz SA, Apel A, Kuhle J, Kaeser SA, Barro C, et al. Serum neurofilament dynamics predicts neurodegeneration and clinical progression in presymptomatic Alzheimer's disease. Nat Med 2019;25(2):277-83.

2. Jack Jr CR, Bennett DA, Blennow K, Carrillo MC, Dunn B, Haeberlein SB, et al. NIA-AA research framework: toward a biological definition of Alzheimer's disease. Alzheimers Dement 2018;14(4):535-62.

3. Lue LF, Guerra A, Walker DG. Amyloid beta and tau as Alzheimer's disease blood biomarkers: promise from new technologies. Neurol Ther 2017;6(1):25-36.

4. Strittmatter WJ, Saunders AM, Schmechel D, Pericak-Vance M, Enghild J, Salvesen GS, et al. Apolipoprotein E: highavidity binding to beta-amyloid and increased frequency of type 4 allele in late-onset familial Alzheimer disease. Proc Natl Acad Sci USA 1993;90(5):1977-81.

5. Jack Jr CR, Albert MS, Knopman DS, McKhann GM, Sperling $\mathrm{RA}$, Carrillo MC, et al. Introduction to the recommendations from the National Institute on Aging-Alzheimer's Association workgroups on diagnostic guidelines for Alzheimer's disease. Alzheimers Dement 2011;7(3):257-62.

6. Ji Y, Urakami K, Adachi Y, Maeda M, Isoe K, Nakashima K. Apolipoprotein E polymorphism in patients with Alzheimer's disease, vascular dementia and ischemic cerebrovascular disease. Dement Geriatr Cogn Disord 1998;9(5):243-5.

7. Mattsson N, Cullen NC, Andreasson U, Zetterberg H, Blennow K. Association between longitudinal plasma neurofilament light and neurodegeneration in patients with Alzheimer disease. JAMA Neurol 2019;76(7):791-9.

8. Lewczuk P, Ermann N, Andreasson U, Schultheis C, Podhorna $\mathrm{J}$, Spitzer P, et al. Plasma neurofilament light as a potential biomarker of neurodegeneration in Alzheimer's disease. Alzheimers Res Ther 2018;10(1):1-10.

9. Bridel C, Van Wieringen WN, Zetterberg H, Tijms BM, Teunissen CE, Alvarez-Cermeno JC, et al. Diagnostic value of cerebrospinal fluid neurofilament light protein in neurology: a systematic review and meta-analysis. JAMA Neurol 2019;76(9):1035-48.

10. Mattsson N, Andreasson U, Zetterberg H, Blennow K, Alzheimer's Disease Neuroimaging Initiative. Association of plasma neurofilament light with neurodegeneration in patients with Alzheimer disease. JAMA Neurol 2017;74(5):557-66.

11. Jack Jr CR, Knopman DS, Jagust WJ, Shaw LM, Aisen PS, Weiner MW, et al. Hypothetical model of dynamic biomarkers of the Alzheimer's pathological cascade. Lancet Neurol 2010;9(1):119-28.

12. Lewczuk P, Esselmann H, Otto M, Maler JM, Henkel AW, Henkel MK, et al. Neurochemical diagnosis of Alzheimer's dementia by CSF $\mathrm{A} \beta 42, \mathrm{~A} \beta 42 / \mathrm{A} \beta 40$ ratio and total tau. Neurobiol Aging 2004;25(3):273-81.

13. Mattsson N, Zetterberg H, Janelidze S, Insel PS, Andreasson U, Stomrud E, et al. Plasma tau in Alzheimer disease. Neurology 2016;87(17):1827-35.

14. Koldamova R, Fitz NF, Lefterov I. The role of ATPbinding cassette transporter A1 in Alzheimer's disease and neurodegeneration. Biochim Biophys Acta 2010;1801(8):82430 . 
15. De Roeck A, Van den Bossche T, van der Zee J, Verheijen J, De Coster W, Van Dongen J, et al. Deleterious ABCA7 mutations and transcript rescue mechanisms in early onset Alzheimer's disease. Acta Neuropathol 2017;134(3):475-87.

16. Cohen D, Eisdorfer C, Walford RL. Histocompatibility antigens (HLA) and patterns of cognitive loss in dementia of the Alzheimer type. Neurobiol Aging 1981;2(4):277-80.

17. Walford RL, Fortoul T. Histocompatibility locus antigens in Alzheimer's disease. Alzheimer's disease. The Standard reference. Macmillan, London, New York; 1983:166-9.

18. Ruiz A, Dols-Icardo O, Bullido MJ, Pastor P, RodriguezRodriguez E, de Munain AL, et al. Assessing the role of the TREM2 p. R47H variant as a risk factor for Alzheimer's disease and frontotemporal dementia. Neurobiol Aging 2014;35(2):444-e1.

19. Bian L, Yang JD, Guo TW, Duan Y, Qin W, Sun Y, et al. Association study of the A2M and LRP1 genes with Alzheimer disease in the Han Chinese. Biol Psychiatry 2005;58(9):731-7.

20. Levy-Lahad E, Wasco W, Poorkaj P, Romano DM, Oshima J, Pettingell WH, et al. Candidate gene for the chromosome 1 familial Alzheimer's disease locus. Science 1995;269:973-7.

21. Sherrington R, Rogaev EI, Liang YA, Rogaeva EA, Levesque $\mathrm{G}$, Ikeda $\mathrm{M}$, et al. Cloning of a gene bearing missense mutations in early-onset familial Alzheimer's disease. Nature 1995;375:754-60.

22. Chartier-Harlin MC, Crawford F, Houlden H, Warren A, Hughes D, Fidani L, et al. Early-onset Alzheimer's disease caused by mutations at codon 717 of the $\beta$-amyloid precursor protein gene. Nature 1991;353:844-6.

23. Goate A, Chartier-Harlin MC, Mullan M, Brown J, Crawford F, Fidani L, et al. Segregation of a missense mutation in the amyloid precursor protein gene with familial Alzheimer's disease. Nature 1991;349:704-6.

24. Gomez-Isla T, West HL, Rebeck GW, Harr SD, Growdon $\mathrm{JH}$, Locascio JJ, et al. Clinical and pathological correlates of apolipoprotein E $\varepsilon 4$ in Alzheimer's disease. Ann Neurol 1996;39(1):62-70.
25. Genin E, Hannequin D, Wallon D, Sleegers K, Hiltunen $\mathrm{M}$, Combarros O, et al. APOE and Alzheimer disease: a major gene with semi-dominant inheritance. Mol Psychiatry 2011;16(9):903-7.

26. Greenberg BD. The COOH-terminus of the Alzheimer amyloid $\mathrm{A} \beta$ peptide: Differences in length influence the process of amyloid deposition in Alzheimer brain, and tell us something about relationships among parenchymal and vessel-associated amyloid deposits. Amyloid 1995;2(3):195-203.

27. Shahim P, Gren M, Liman V, Andreasson U, Norgren N, Tegner $\mathrm{Y}$, et al. Serum neurofilament light protein predicts clinical outcome in traumatic brain injury. Sci Rep 2016;6(1):1-9.

28. De Marchis GM, Katan M, Barro C, Fladt J, Traenka C, Seiffge DJ, et al. Serum neurofilament light chain in patients with acute cerebrovascular events. Eur J Neurol 2018;25(3):562-8.

29. Disanto G, Barro C, Benkert P, Naegelin Y, Schadelin S, Giardiello A, et al. Serum neurofilament light: a biomarker of neuronal damage in multiple sclerosis. Ann Neurol 2017;81(6):857-70.

30. Thaker U, McDonagh AM, Iwatsubo $\mathrm{T}$, Lendon $\mathrm{CL}$, Pickering-Brown SM, A Mann DM. Tau load is associated with apolipoprotein $\mathrm{E}$ genotype and the amount of amyloid $\beta$ protein, A $\beta 40$, in sporadic and familial Alzheimer's disease. Neuropathol Appl Neurobiol 2003;29(1):35-44.

31. Lippa CF, Saunders AM, Smith TW, Swearer JM, Drachman DA, Ghetti B, et al. Familial and sporadic Alzheimer's disease: neuropathology cannot exclude a final common pathway. Neurology 1996;46(2):406-12.

This is an open access article distributed under the terms of the Creative Commons Attribution-NonCommercial-ShareAlike 3.0 License, which allows others to remix, tweak, and build upon the work non-commercially, as long as the author is credited and the new creations are licensed under the identical terms

This article was originally published in a special issue,
"Therapeutic Perspectives in Biomedical Research and Pharma-
ceutical Sciences and their Nursing Methods"
Indian J Pharm Sci 2021:83(4)Spl issue "253-259"

